\title{
Viscoelasticity and Damage Model for Creep Behavior of Historical Masonry Structures
}

\author{
Pere Roca, Miguel Cervera, Luca Pelà*, Roberto Clemente and Michele Chiumenti
}

Technical University of Catalonia (UPC), Campus Norte, Jordi Girona 1-3, 08034 Barcelona, Spain

\begin{abstract}
This paper presents a continuum model for the simulation of the viscous effects and the long-term damage accumulation in masonry structures. The rheological model is based on a generalized Maxwell chain representation with a constitutive law utilizing a limited number of internal variables. Thanks to its computational efficiency, this approach is suitable for the analysis of large and complex structures. In the paper, the viscous and damage models are presented and their coupling is discussed. The FE simulation of the construction process of the representative bay of Mallorca Cathedral is presented, together with the analysis of the long-term effects. The parameters of the model are tentatively calibrated on the basis of the time-dependent viscous deformations detected during the cathedral monitoring.
\end{abstract}

Keywords: Masonry, Viscosity, Creep, Damage Accumulation, Long-term effects, Geometric Nonlinearity, Historical Constructions, Gothic Cathedral.

\section{INTRODUCTION}

Masonry constructions may experience significant deterioration progresses, even without change in loading conditions, due to effect of long-term deformation and damage accumulation [1-4]. Sudden collapses of historical structures like the Pavia Civic Tower and the Noto Cathedral $[5,6]$ or the need for urgent interventions, such as in Monza Cathedral bell tower [7, 8], have increased the research interest on the long-term behavior of masonry constructions. The assessment of their stability and time-dependent structural behavior required the development of appropriate numerical tools that can calculate the time-dependent deformation and damage accumulation in quasi-brittle materials under monotonic and sustained stresses. The available proposed models differ in the hypotheses, theoretical frameworks, the level of detail and complexity [9-11].

This paper presents a viscoelasticity and damage model intended for the analysis of complex historical structures. The theoretical framework is characterized by a simple formulation limiting the necessary number of experimentally deduced model parameters. The constitutive law for the viscoelastic and damaging material can be written in terms of a limited number of internal variables, resulting in a considerable computational advantage. Suitable damage variables are coupled to the rheological model in order to describe the material behavior under stresses either increasing or constant in time.

The constitutive model is presented and the time integration procedure for their implementation into a FE code is

*Address correspondence to this author at the Technical University of Catalonia (UPC), Campus Norte, Jordi Girona 1-3, 08034 Barcelona, Spain; Tel: +34 934011036; Fax: +34 934054135; E-mail; luca.pela@upc.edu detailed. The application of the model to the numerical study of a representative bay of Mallorca Cathedral is discussed. The procedure to identify the parameters that define the viscous and damage model, starting from the experimental monitoring activity, is also described. The parameters of the model have been calibrated using a 5-year monitoring period. In spite of it, the study has mostly a tentative character given the important uncertainties and difficulties involved. One of the main difficulties is found in the estimation of the initial deformation of the structure after construction. In the present study, an attempt towards an estimation of this deformation is carried out through a sequential analysis involving two construction phases suggested by the historical research carried out on the building.

The structure shows significant deformation which, according to previous studies [12], can be related with the combined effects of construction process undergoing delicate intermediate stages, long-term deformation and geometric non-linearity. The research presented aim to explore the viability of a numerical simulation of deformation and damage taking into account these combined effects.

\section{VISCOELASTICITY MODEL}

The underlying viscoelasticity model adopted in this work was proposed by Cervera [13]. The model has been adapted to the study of masonry structures with the aim of simulating the time-dependent strain accumulation in the material as a result of long-term exposure to constant stress. The main idea of the approach is modelling the timedependent deformation through a time-dependent stiffness defined by two components corresponding to a constant one and a viscosity susceptible one. 
Compact tensor notation is used in this paper. As general rule, scalars are denoted by light-face italic letters; vectors and second-order tensors are signified by boldface minuscule letters; fourth-order tensors are identified by boldface majuscule letters.

\subsection{Constitutive Model}

The behavior of the model is presented firstly considering a simple one-dimension representation by means of Hookean spring elements and dashpots (Fig. 1). However, the model is fully three-dimensional. The generalization to multiaxial stress states is presented afterwards, together with the relevant tensorial governing equations.

Fig. (1a) shows a schematization of the adopted rheological model for the uniaxial case, which is built as a combination of two elements, consisting respectively of a single spring and a Maxwell chain including a spring arranged in series with a dashpot. The uniaxial model is defined by three parameters, i.e. the elastic stiffness of the first spring $E_{\infty}$, that of the second spring $E_{v}$ and the viscosity parameter $\eta$ corresponding to the dashpot. The viscous stress in the dashpot is proportional to the viscous strain rate, i.e. $\sigma_{v}=\eta \dot{\varepsilon}_{v}$.

Due to its viscous response, the dashpot of the Maxwell chain is infinitely stiff at the beginning of the deformation process, while its stiffness tends to zero for infinite time. Hence, the initial stiffness of the system is given by the sum of the stiffnesses of the two springs and the instantaneous elastic modulus $E_{0}$ can be calculated as follows:

$$
E_{0}=E_{\infty}+E_{v}
$$

Similarly, the stiffness of the system for $t=+\infty$ is equal to $E_{\infty}$, since the dashpot is completely slackened at the end of the deformation process. The term $\xi=E_{v} / E_{0}$, called participation ratio, defines the amount of stiffness susceptible to experience viscosity.

The addition of the stresses in the two elements results in the total stress sustained by the system:

$$
\sigma=\sigma_{e}+\sigma_{v}=E_{\infty} \varepsilon+\xi E_{0}\left(\varepsilon-\varepsilon_{v}\right)
$$

In the above equation, $\varepsilon$ represents the total deformation of the system (Fig. 1b), whereas $\varepsilon_{v}$ denotes the viscous
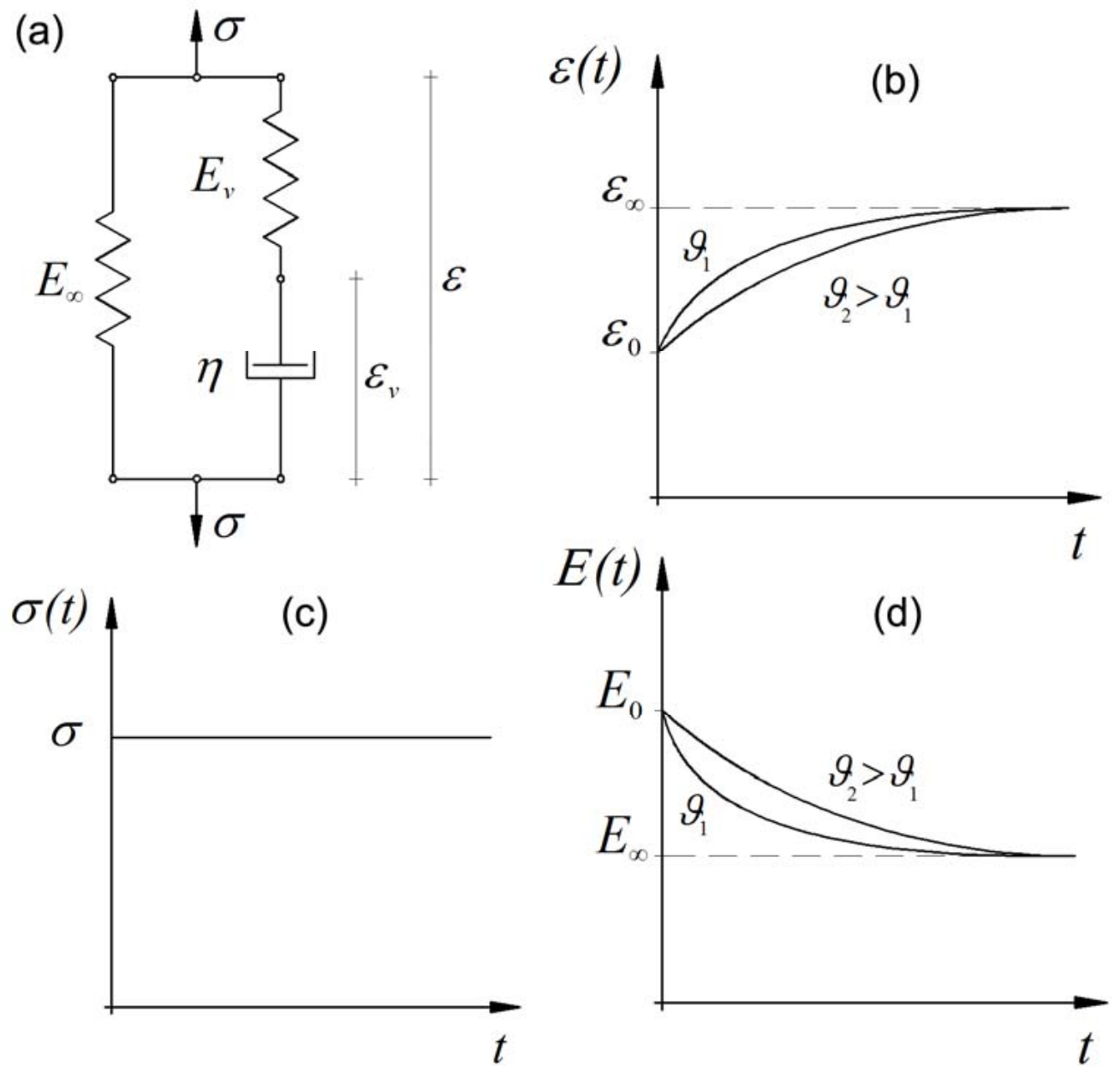

Fig. (1). Maxwell chain schematization of the viscoelasticity model (a) and time-dependent laws: strain (b), stress (c) and stiffness (d). 
strain of the chain which increases with time under a constant stress $\sigma$ (Fig. 1c). The final deformation $\varepsilon_{\infty}=\sigma / E_{\infty}$ can be also written in the following form:

$\varepsilon_{\infty}=\left(1+\varphi_{\infty}\right) \varepsilon_{0}$

In which $\varepsilon_{0}=\sigma / E_{0}$ is the instantaneous deformation and $\varphi_{\infty}=E_{v} / E_{\infty}$ is the creep coefficient commonly utilized in structural design codes to denote the relationship between the instantaneous and the final deformation. This coefficient can be easily related to the aforementioned participation ratio through the equation

$\varphi_{\infty}=\frac{\xi}{1-\xi}$

The effect of the so-called retardation time $\vartheta=\eta / E_{v}$ on the time-dependent increase of strain or decrease of stiffness is depicted in Figs $(\mathbf{1 b}, \mathbf{d})$. This parameter defines the time scale of the viscous phenomenon since it is linked to the time necessary for dashpot relaxation.

The strain rate of the system is defined by the following equation:

$\dot{\varepsilon}=\frac{\dot{\sigma}_{v}}{E_{v}}+\frac{\sigma_{v}}{\eta}$

Multiplying each term by $E_{v}$ it is possible to obtain the first order differential equation governing the evolution of the variable $\sigma_{v}$ :

$\xi E_{0} \dot{\varepsilon}=\dot{\sigma}_{v}+\frac{\sigma_{v}}{\vartheta}$

In the multidimensional case the model is written in terms of the isotropic linear-elastic constitutive tensor $\mathbf{C}$, the strain tensor $\boldsymbol{\varepsilon}$ and the viscous stress tensor $\boldsymbol{\sigma}_{v}$. The elastic constants in tensor $\mathbf{C}$ are the aforementioned instantaneous Young's modulus $\mathrm{E}_{0}$ and the Poisson's ratio $v_{0}$. The instantaneous shear modulus is $G_{0}=E_{0} / 2\left(1+v_{0}\right)$. Accordingly, the model reads:

$$
\xi \mathbf{C}: \dot{\boldsymbol{\varepsilon}}=\dot{\boldsymbol{\sigma}}_{v}+\frac{\boldsymbol{\sigma}_{v}}{\vartheta}
$$

With the aim of assuming the viscous strain in the Maxwell chain as internal variable, the relationship

$\boldsymbol{\sigma}_{v}=\xi \mathbf{C}:\left(\boldsymbol{\varepsilon}-\boldsymbol{\varepsilon}_{v}\right)$

Can be included in Equation (7), leading finally to the evolution law for the viscous strain:

$\dot{\boldsymbol{\varepsilon}}_{v}=\frac{1}{\vartheta}\left(\boldsymbol{\varepsilon}-\boldsymbol{\varepsilon}_{v}\right)$
The intrinsic multiaxial character of Equations (7-9) considers the viscous effects in all possible stress/strain states of the material. It is worth noticing that the scalar character of the parameters $\xi$ and $\vartheta$ in Equations (7-9) implies that all of the stress/strain components are affected by viscosity in the same measure. The model could be improved by considering different participation ratios and relaxation times along the different material axes, i.e. by replacing $\xi$ and $\vartheta$ with tensors. However, this possible enhancement has not been considered in this work since it would deserve a comprehensive experimental investigation to determine the directional variability of the viscous evolution laws in masonry. On the other hand, the orthotropic elastic behavior of masonry could be taken into account by considering an orthotropic linear constitutive tensor $\mathbf{C}$, but this approach has not been considered so far for the analysis of Mallorca Cathedral due to lack of sophisticated mechanical characterization of materials.

\subsection{Integration of the Internal Variables}

The solution of the differential equation for a generic time step $t_{n+1}$ has the form

$\boldsymbol{\varepsilon}_{v}\left(t_{n+1}\right)=\frac{1}{\vartheta} \int_{-\infty}^{t_{n+1}} e^{-t_{n+1}-s} \vartheta(s) d s$

Following a time incremental procedure, i.e. $t_{n+1}=t_{n}+\Delta t$, it is possible to obtain

$\boldsymbol{\varepsilon}_{v}\left(t_{n+1}\right)=\frac{1}{\vartheta} \int_{-\infty}^{t_{n}} e^{-\frac{t_{n}-s}{\vartheta}} e^{-\frac{\Delta t}{\vartheta}} \boldsymbol{\varepsilon}(s) d s+\frac{1}{\vartheta} \int_{t_{n}}^{t_{n+1}} e^{-\frac{t_{n+1}-s}{\vartheta}} \boldsymbol{\varepsilon}(s) d s$

hence

$\boldsymbol{\varepsilon}_{v}\left(t_{n+1}\right)=\boldsymbol{\varepsilon}_{v}\left(t_{n}\right) e^{-\frac{\Delta t}{9}}+\Delta \boldsymbol{\varepsilon}_{v}$

being the viscous strain increment equal to

$\Delta \boldsymbol{\varepsilon}_{v}=\frac{1}{\vartheta} \int_{t_{n}}^{t_{n+1}} e^{-\frac{t_{n+1}-s}{\vartheta}} \boldsymbol{\varepsilon}(s) d s$

Assuming that strain remains almost constant during the interval $\left[t_{n}, t_{n+1}\right]$ and equal to the value at time $\bar{t}$, with $\bar{t}=t_{n}+\alpha \Delta t, 0 \leq \alpha \leq 1$, Equation (13) can be rewritten as

$$
\begin{aligned}
& \Delta \boldsymbol{\varepsilon}_{v}=\frac{1}{\vartheta} \boldsymbol{\varepsilon}(\bar{t}) \int_{t_{n}}^{t_{n+1}} e^{-\frac{t_{n+1}-s}{\vartheta}} d s=\boldsymbol{\varepsilon}(\bar{t}) e^{-\frac{t_{n+1}}{\vartheta}\left[e^{\frac{s}{\vartheta}}\right]_{t_{n}}^{t_{n+1}}} \\
& =\boldsymbol{\varepsilon}(\bar{t})\left(1-e^{-\frac{\Delta t}{\vartheta}}\right)
\end{aligned}
$$

If previous expression is substituted in Equation (12), the results is 
$\boldsymbol{\varepsilon}_{v}\left(t_{n+1}\right)=\boldsymbol{\varepsilon}_{v}\left(t_{n}\right) e^{-\frac{\Delta t}{\vartheta}}+\boldsymbol{\varepsilon}(\bar{t})\left(1-e^{-\frac{\Delta t}{\vartheta}}\right)$

Assuming $\alpha=0$, it would result $\boldsymbol{\varepsilon}(\bar{t})=\boldsymbol{\varepsilon}\left(t_{n}\right)$ and it would be necessary to store the previous time step total strain to integrate the viscous strain. Hence, it is more efficient to consider $\alpha=1$, since it results $\boldsymbol{\varepsilon}(\bar{t})=\boldsymbol{\varepsilon}\left(t_{n+1}\right)$ and Equation (12) reduces to

$\boldsymbol{\varepsilon}_{v}\left(t_{n+1}\right)=\boldsymbol{\varepsilon}_{v}\left(t_{n}\right) e^{-\frac{\Delta t}{\vartheta}}+\boldsymbol{\varepsilon}\left(t_{n+1}\right)\left(1-e^{-\frac{\Delta t}{\vartheta}}\right)$

It is worth noticing that this integration method is unconditionally stable. For small time steps, $\Delta t / \vartheta<<1$, $e^{-\frac{\Delta t}{\vartheta}} \approx 1-\frac{\Delta t}{\vartheta}$ and Equation (16) can be rewritten finally as

$\boldsymbol{\varepsilon}_{v}\left(t_{n+1}\right)=\boldsymbol{\varepsilon}_{v}\left(t_{n}\right)+\frac{\Delta t}{\vartheta}\left[\boldsymbol{\varepsilon}\left(t_{n+1}\right)-\boldsymbol{\varepsilon}_{v}\left(t_{n}\right)\right]$

\section{DAMAGE MODEL}

\subsection{Constitutive Model}

In order to describe the stress-stain relationships a damage-theory based model is adopted based on the concept of effective stress tensor $\overline{\boldsymbol{\sigma}}$ related to strains $\boldsymbol{\varepsilon}$ under elastic regimen:

$\overline{\boldsymbol{\sigma}}=\mathbf{C}: \boldsymbol{\varepsilon}$

where $\mathbf{C}$ is the isotropic linear-elastic constitutive tensor.

The mechanical damage in masonry due to cracking and crushing is described by the Tension-Compression Damage Model [14,15]. According to this model, and according to the different mechanical behavior in tension and compression, a split of the effective stress tensor into tensile and compressive components, $\overline{\boldsymbol{\sigma}}^{+}$and $\overline{\boldsymbol{\sigma}}^{-}$, is introduced according to:

$\overline{\boldsymbol{\sigma}}^{+}=\sum_{i=1}^{3}\left\langle\bar{\sigma}_{i}\right\rangle \mathbf{p}_{i} \otimes \mathbf{p}_{i} \quad$ and $\quad \overline{\boldsymbol{\sigma}}^{-}=\overline{\boldsymbol{\sigma}}-\overline{\boldsymbol{\sigma}}^{+}$

where $\bar{\sigma}_{i}$ denotes the $i$-th principal stress value from tensor $\overline{\boldsymbol{\sigma}}, \mathbf{p}_{i}$ represents the unit vector associated with its respective principal direction and the symbols $\langle$.$\rangle are the Macau-$ lay brackets $(\langle x\rangle=x$, if $x \geq 0,\langle x\rangle=0$, if $x<0)$.

The constitutive equation takes the form:

$\boldsymbol{\sigma}=\left(1-d^{+}\right) \overline{\boldsymbol{\sigma}}^{+}+\left(1-d^{-}\right) \overline{\boldsymbol{\sigma}}^{-}$

where $d^{+}$and $d^{-}$, are internal damage variables each related with the sign of the stress and thus with tension and compression. The internal damage variables are equal to zero when the material is undamaged and equal to one when it is completely damaged.

Different damage criteria are assumed for tension and compression stress states in order to describe the corresponding damage types (cracking and crushing). The damage functions are defined as:

$\Phi^{ \pm}\left(\tau^{ \pm}, r^{ \pm}\right)=\tau^{ \pm}-r^{ \pm} \leq 0$

being $\tau^{ \pm}$scalar positive quantities, termed as equivalent stresses and defined in order to compare different stress states in two- or three-dimensions:

$\tau^{ \pm}=\left[\overline{\boldsymbol{\sigma}}^{ \pm}: \boldsymbol{\Lambda}^{ \pm}: \overline{\boldsymbol{\sigma}}^{ \pm}\right]^{1 / 2}$

The shape of each damage criterion is defined by tensors $\boldsymbol{\Lambda}^{ \pm}$. In this work, for the particular case of masonry material, it is assumed that $\boldsymbol{\Lambda}^{+}=\mathbf{p}_{1} \otimes \mathbf{p}_{1} \otimes \mathbf{p}_{1} \otimes \mathbf{p}_{1}$, which corresponds to the Rankine criterion in tension, while for the compression case it is assumed that $\mathbf{\Lambda}^{-}=\mathbf{C} / E$, where $E$ is the Young's modulus. Fig. (2) shows the resulting representation of the composite damage criterion for the twodimensional case.

Variables $r^{ \pm}$are internal stress-like variables representing the current damage threshold and their values control the size of the (monotonically) expanding damage surface. The initial values of the damage thresholds are $r_{0}^{ \pm}=f^{ \pm}$, where $f^{+}$and $f^{-}$are the uniaxial strengths in tension and compression. The evolution law of the internal variables $r^{ \pm}$is explicitly defined in the following way:

$r^{ \pm}=\max \left[r_{0}^{ \pm}, \max \left(\tau^{ \pm}\right)\right]$

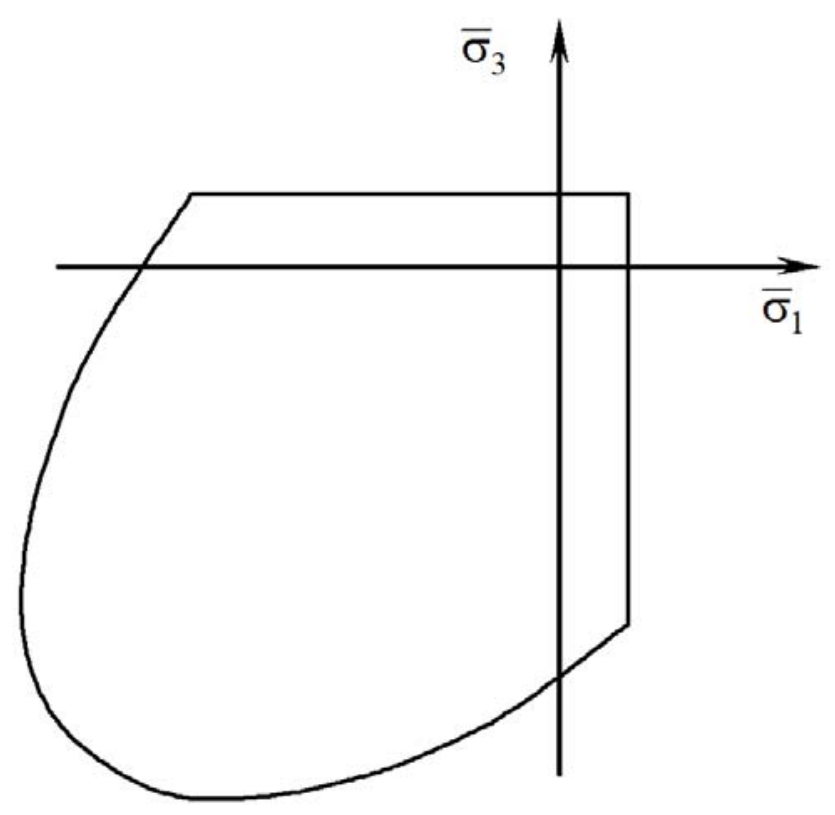

Fig. (2). Composite damage surface. 
Finally, the damage indexes $d^{ \pm}$are defined in terms of the corresponding current value of the damage thresholds $r^{ \pm}$in the form of a monotonically increasing function such that $0 \leq d^{ \pm}\left(r^{ \pm}\right) \leq 1$. In this work, the following exponential expressions are assumed

$$
d^{ \pm}\left(r^{ \pm}\right)=1-\frac{r_{0}^{ \pm}}{r^{ \pm}} \exp \left\{2 H_{d i s}^{ \pm}\left(\frac{r_{0}^{ \pm}-r^{ \pm}}{r_{0}^{ \pm}}\right)\right\}
$$

where constants $H_{\text {dis }}^{ \pm} \geq 0$ are the discrete softening parameters [16]. They are related to material tensile and compressive fracture energies $G_{f}^{ \pm}$, normalized according to the finite element characteristic length, in order to ensure objectivity of the FEM solution respect to the mesh size [17].

It is worth noticing that more sophisticated damage models could be adopted, including also the orthotropic behavior with different stiffnesses, strengths and inelastic responses along the different material axes [18]. The choice of a simple model was adopted in this work as a first approach to the study of a complex historical masonry structure.

\subsection{Coupling with Viscoelasticity}

The coupling of the tension-compression damage model with the viscoelasticity model is carried out by assuming that the stress sustained by the Maxwell chain is the effective (undamaged) stress, rather than the total stress [19]. Therefore, Equation (2) can be rewritten as follows:

$$
\overline{\boldsymbol{\sigma}}=\overline{\boldsymbol{\sigma}}_{e}+\overline{\boldsymbol{\sigma}}_{v}=(1-\xi) \mathbf{C}: \boldsymbol{\varepsilon}+\xi \mathbf{C}:\left(\boldsymbol{\varepsilon}-\boldsymbol{\varepsilon}_{v}\right)
$$

The split of the effective stresses in each chain element is carried out, according to Equation (19), leading to:

$$
\overline{\boldsymbol{\sigma}}^{+}=\overline{\boldsymbol{\sigma}}_{e}^{+}+\overline{\boldsymbol{\sigma}}_{v}^{+} \text {and } \overline{\boldsymbol{\sigma}}^{-}=\overline{\boldsymbol{\sigma}}_{e}^{-}+\overline{\boldsymbol{\sigma}}_{v}^{-}
$$

Finally, the constitutive model in Equation (20) can be rewritten to account for the coupling between viscoelasticity and mechanical damage:

$$
\boldsymbol{\sigma}=\left(1-d^{+}\right)\left(\overline{\boldsymbol{\sigma}}_{e}^{+}+\overline{\boldsymbol{\sigma}}_{v}^{+}\right)+\left(1-d^{-}\right)\left(\overline{\boldsymbol{\sigma}}_{e}^{-}+\overline{\boldsymbol{\sigma}}_{v}^{-}\right)
$$

It is worth noticing that the damage criteria, the evolution of damage indexes and thresholds are expressed in terms of the effective stresses (see Equation 22) and hence of the strains increasing with time. This format of the model is essential to describe properly the accumulation of mechanical damage under constant stress in masonry material.

\section{APPLICATION TO MALLORCA CATHEDRAL}

This section presents the application of the proposed model for the analysis of the representative bay of Mallorca Cathedral. Firstly, the current state of deformation detected on the structure during the monitoring activity is presented. Secondly, the FE analysis of the structure is carried out in order to investigate the possible influence of construction process and long-term deformation on the present condition. The study of Mallorca cathedral is considered as a way to assess the actual applicability of the numerical tool for the analysis of long term deformation and damage in a real large structure.

\subsection{Current Deformation in mallorca Cathedral}

The construction of the Cathedral of Mallorca, Spain, started in year 1306 and spanned to year 1600, with a long interruption period from 1460 to 1560 . On the basis of historical documents [20-22], it was possible to understand the construction process, which consisted in building sequentially the adjoining bays from the presbytery following the longitudinal direction. The cathedral, with overall dimensions of $121 \mathrm{~m}$ in length and $55 \mathrm{~m}$ in width, is one of the most imposing Gothic buildings of the Mediterranean area (Fig. 3).

The piers have an octagonal section with circumscribed diameter of 1.6 or $1.7 \mathrm{~m}$ and a height of $22.7 \mathrm{~m}$ to the springing of the lateral vaults. Such members show remarkable curvature and lateral displacement especially along the direction transverse to the nave (Fig. 4). It was in part this noticeable deformed condition, along with some damage observed in the piers, which led to the decision of undertaking a detailed study of the building including monitoring to measure the evolution of the crack opening and deformation. The study of the building included also a detailed survey of the current deformed condition. Remarkably, it was observed that the deformation in piers does not show a systematic pattern, but appears in a rather random way showing very variable maximum values and predominant direction (inward or outward to the nave). The maximum lateral displacement measured in piers ranges from $2 \mathrm{~cm}$ up to, in a single case, $26 \mathrm{~cm}$, with an average (in absolute value) of $13 \mathrm{~cm}$ corresponding to a ratio of 1/115 with respect to the height.

According to calculations carried out for the present deformed configuration, considering the $2^{\text {nd }}$ order effects, the stability of the structure under dead load is at the moment not compromised by the existing deformation. Nevertheless the detected trend towards a progressive deformation increase is of concern because, in combination with geometric nonlinear effects, it might worsen the stability conditions and eventually lead to instability. For this reason, a FE analysis of the representative bay has been carried out using the constitutive models described in the previous sections, to study the long-term behavior of the structure.

The in-situ measures of pier horizontal displacements have been processed to assess the order of magnitude of the net movements of the structure for the comparison with the numerical results. The in-situ measures show a certain trend towards a global lateral displacement in the direction perpendicular to the nave. This trend is recognizable as an unsymmetrical deformation component. Due to this asymmetric character, this component of the deformation cannot be directly linked to the effect of the gravity forces and, based on some geological evidence, is in principle attributed to an overall deformation of the rocky platform on which the building is founded.

A simple mathematical criterion has been applied to decompose the overall displacement values into symmetric and asymmetric components, of which only the first can be re- 


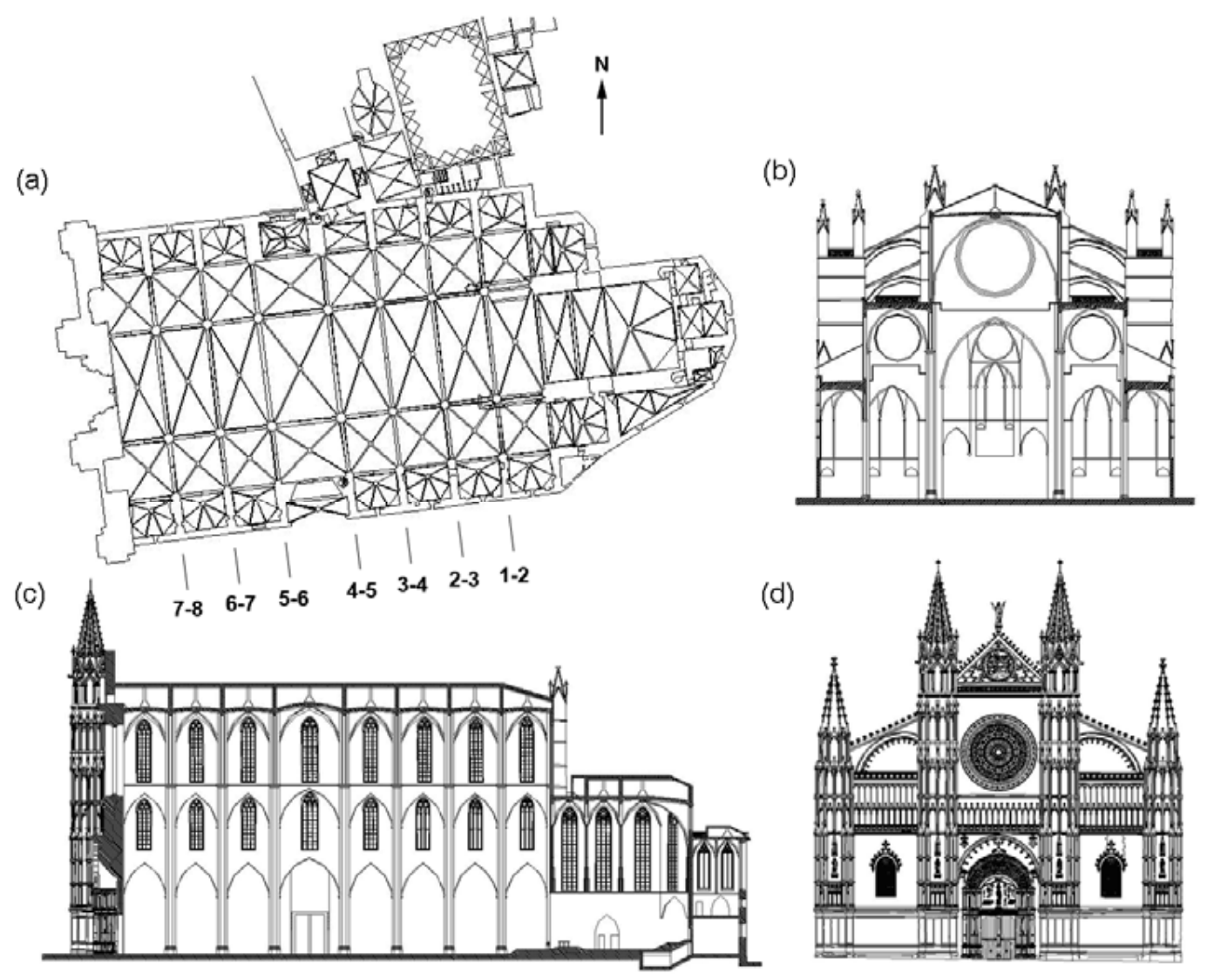

Fig. (3). Mallorca Cathedral: plan at roof level (a), transverse section (b), longitudinal section (c) and façade (d).

lated to gravity effects. It is possible to decompose each couple of horizontal displacements $\delta_{l}$ and $\delta_{r}$ of two symmetric points into an asymmetric displacement $\delta_{a}=\left(\delta_{l}+\delta_{r}\right) / 2$ and a symmetric displacement $\delta_{s}=\left(\delta_{l}-\delta_{r}\right) / 2$. This operation has been carried out considering the displacements of the points at the top of the piers (23 m high) and at the springings of the central vault (30 $\mathrm{m}$ high). All the values obtained are listed in Table $\mathbf{1}$ for the different nave sections denoted in Fig. (3a). The last column of the table also reports the horizontal displacements $\delta_{t}$ at the top of the central nave. As shown, the orders of magnitude of $\delta_{a}$ and $\delta_{t}$ are often comparable, thus the decomposition of $\delta_{l}$ and $\delta_{r}$ into the asymmetric and symmetric components seems an acceptable approximation. Although the resulting symmetric displacements are still showing a significant variation among the different bays, the procedure allows for some reduction of the range of variation. The resulting values $\delta_{s}$ are believed to be more representative than the total ones of the long-term deformation experienced by the structure under sustained gravity loading. The symmetric displacement $\delta_{s}$ at the height of $23 \mathrm{~m}$ are bounded by $4 \mathrm{~cm}$ and $16 \mathrm{~cm}$, showing a clear range of values to be compared with the results derived from a symmetric FE model subject to gravitational loading.

It is worth noticing that despite the processing of experimental data, the measures in Table $\mathbf{1}$ still present a considerable scatter. This may be due to the building process of the cathedral, since it involved a very long period of time and

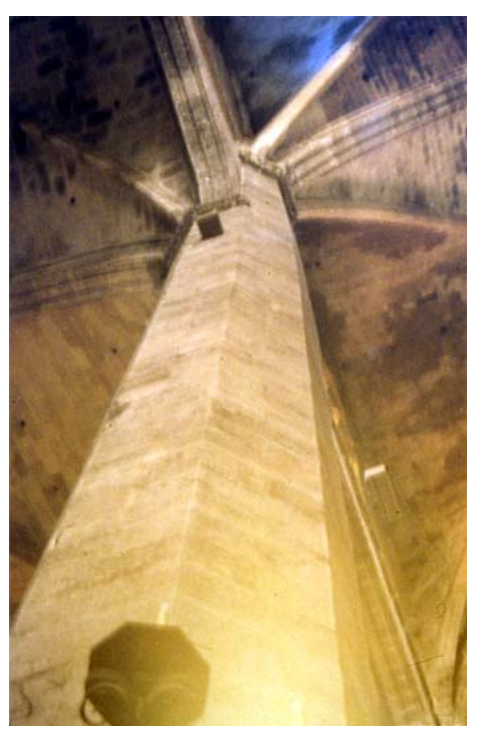

Fig. (4). Deformation at the top of a pier. 
important periods elapsed between the construction of adjacent bays or even during the construction of a single one. In particular, and because of this long construction period, involving many generations, varying construction approaches may have been utilized for building different parts of the structure and to overcome the difficulties posed by the intermediate construction stages. As an example, it is remarkable that the first two bays (from the choir to section 3-4 of Fig. 3a) are built with more slender piers compared with the rest of the bays; the diameter of the pier was probably modified (from 1.5 to $1.7 \mathrm{~m}$ ) as a correction due to problems encountered during the construction of the first bays.

The complete construction chronology has been investigated in detail in the case of the $4^{\text {th }}$ bay based on the documents available in the files of the Chapter of Mallorca Cathedral. The construction process started with the lateral chapels, followed by the piers, then lateral vaults and finally the central one. During the last stage before the construction of the central vault, the piers were already receiving the inward thrust of the lateral naves, while the absence of the central one did not provide for any counteracting action, thus creating a delicate stability condition. In the case of this bay, the construction of the vaults lasted for 7 years, with some interruptions. The available documents do not provide any clue on the utilization of provisional stabilizing devices, such as iron ties or timber struts, although their use cannot be totally disregarded. The possibility that the master builders relied solely on the self-capacity of the vaults to keep stable during a limited period of time can be also considered, but requires additional investigation on the actual self-stability of the partial system during at least a limited period of time.

The monitoring of the building started in September 2003 and was interrupted in September 2008. In addition to the measurement of climatic parameters, it involved crackmeters to monitor the main cracks, as well as clinometers and long- base extensometers to measure the variation of rotations in pies and distances across different points of the structure. The information recorded was then post-processed in order to decompose all the measurements into their reversible and irreversible components. The reversible trends, by far the most apparent ones, are caused by climatic environmental actions (mainly temperature) while the irreversible ones are linked to possible on-going deterioration and creep. The post-processing of this first monitoring period, encompassing 5 years, detected a gradual and irreversible, although very small, increase of the deformation of the structure. This gradual increase of deformation was noted in an accumulative increase of the opening of major cracks, in the similarly accumulative opening of vaults and arch spans, and also in the lateral displacement of the piers in the direction transverse to the nave. In particular, it was observed that the lateral deformation of piers is at present progressing at a rate of about $0.1 \mathrm{~mm}$ per year.

\subsection{FEM Modelling of the Representative Bay}

Since the present study focuses on the effects of gravity loads, a FEM model involving only one quarter of the typical bay is sufficient in order to carry out the different analyses (Fig. 5). Appropriate boundary conditions have been defined in order to account for symmetry and the effect of the adjacent bays. A continuum macromodelling approach has been considered $[23,24]$. The adopted FE mesh is composed of 49,979 tetrahedral elements and 14,689 nodes. Mesh refinement has been carried out in zones where high stress gradients are expected, as at both ends of flying arches and columns, at the intersection between different structural elements and under the large false window located in buttresses. The model has been defined with different material parameters for the main groups of structural members composing the structure (Table 2).

Table 1. Piers Horizontal Displacements $\left(\delta_{l}, \delta_{r}\right)$, Decomposition Into Asymmetric and Symmetric Components $\left(\delta_{a}\right.$, $\left.\delta_{s}\right)$ and Horizontal Displacements at the Top of the Nave $\left(\delta_{t}\right)$.

\begin{tabular}{|c|c|c|c|c|c|c|}
\hline Section & Height (m) & $\delta_{i}(\mathrm{~cm})$ & $\delta_{r}(\mathrm{~cm})$ & $\delta_{a}(\mathrm{~cm})$ & $\delta_{s}(\mathrm{~cm})$ & $\delta_{t}(\mathbf{c m})$ \\
\hline \multirow{2}{*}{$1-2$} & 23 & 9 & -3 & 3 & 6 & \multirow{2}{*}{11} \\
\hline & 30 & 10 & 8 & 9 & 1 & \\
\hline \multirow{2}{*}{$2-3$} & 23 & 11 & 26 & 18.5 & -7.5 & \multirow{2}{*}{21} \\
\hline & 30 & 4 & 36 & 20 & -16 & \\
\hline \multirow{2}{*}{ 3-4 } & 23 & 19 & -2 & 8.5 & 10.5 & \multirow{2}{*}{19} \\
\hline & 30 & -5 & 36 & 15.5 & -20.5 & \\
\hline \multirow{2}{*}{$4-5$} & 23 & 17 & -2 & 7.5 & 9.5 & \multirow{2}{*}{1} \\
\hline & 30 & 26 & 8 & 17 & 9 & \\
\hline \multirow{2}{*}{$5-6$} & 23 & 18 & 10 & 14 & 4 & \multirow{2}{*}{8} \\
\hline & 30 & 32 & 6 & 19 & 13 & \\
\hline \multirow{2}{*}{$6-7$} & 23 & 20 & -12 & 4 & 16 & \multirow{2}{*}{-4} \\
\hline & 30 & 11 & -18 & -3.5 & 14.5 & \\
\hline \multirow{2}{*}{$7-8$} & 23 & 20 & -7 & 6.5 & 13.5 & \multirow{2}{*}{1} \\
\hline & 30 & 14 & 2 & 8 & 6 & \\
\hline
\end{tabular}



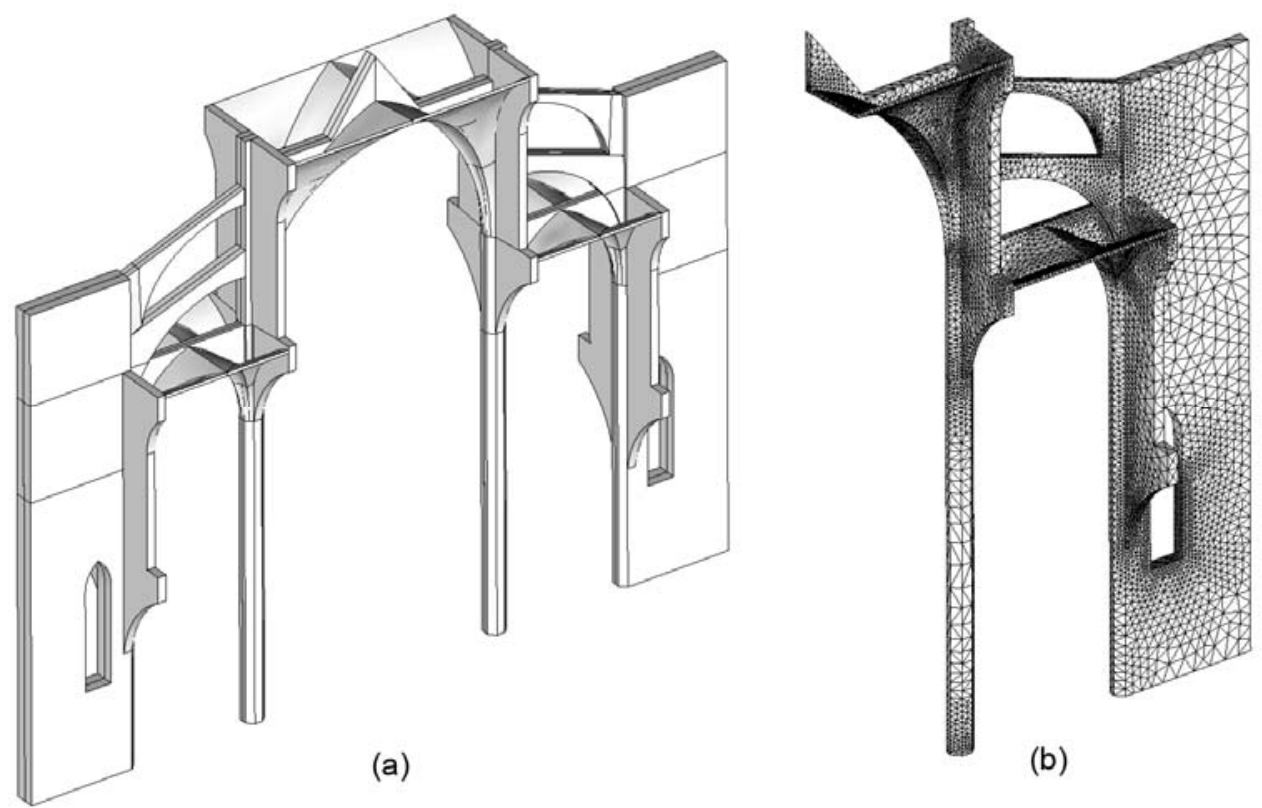

(b)

Fig. (5). Representative bay (a) and FE mesh (b) considered for the FE analysis.

The masonry compressive strength has been estimated based on the values experimentally obtained by means of mechanical tests carried out on stone samples. In the case of the piers, the stone samples were obtained from the original quarries, while in the walls, buttresses and flying arches they were taken in situ.

The tensile strength has been assumed equal to $5 \%$ of the compressive strength. The Young moduli values adopted have been derived from the structural identification procedure reported in [25]. Values for the fracture energies have been assumed based on previous experience, since they were not measured experimentally.

The viscoelasticity and tension-compression models presented in Sections 2-3 have been implemented into the FE program COMET [26] developed at the International Centre for Numerical Methods in Engineering (CIMNE, Barcelona). Pre- and post-processing have been carried out with GiD [27], also developed at CIMNE.

\subsection{Simulation of the Construction Process}

The construction process of the bay has been simulated numerically using a FE activation strategy able to reproduce the addition of different portions of structure during the building stages. The elements of the FE mesh are classified into active and inactive. At the beginning of the analysis, the elements which define the first portion built are activated, i.e. computed and assembled into the global matrix, whereas the inactive elements are disregarded in calculations. In the following step, the elements corresponding to the next construction stage are activated and the calculation proceeds, considering the first portion already deformed. By repeating such procedure until the completion of all building stages, it is possible to obtain a numerical simulation of the whole construction process.

According to the information obtained from historical research, the construction process of the single bay is simulated through three subsequent analysis steps. In the first step, only the lower part of the FE model is activated, including the pier, the aisle vault and the buttress. In the second analysis step, the upper part of the FE model, including the upper part of the buttress, the flying arches, the clerestory and the nave vault, is activated. Finally, the structure is subject to constant loading and the time starts elapsing in order to evaluate the deformation accumulation due to creep. In each subsequent phase, the computation is carried on starting from the stress-strain state obtained at the end of the previous phase. The geometric nonlinearity is taken into account

Table 2. Material Parameters Adopted in Numerical Analyses

\begin{tabular}{|c|c|c|c|c|c|c|c|}
\hline Structural Element & $\gamma$ & $E$ & $v$ & $f^{+}$ & $f^{-}$ & $G_{f}^{+}$ & $G_{f}^{-}$ \\
\hline columns, flying arches & 2400 & 8000 & 0.2 & 0.40 & 8.00 & 100 & 40000 \\
\hline central vault backing & 2000 & 1000 & 0.2 & 0.05 & 1.00 & 100 & 40000 \\
\hline
\end{tabular}


by adopting a total Lagrangian formulation with the assumption of small-strain/large-displacement.

After the first construction phase, with only the lateral vaults built, the resulting horizontal deformation at the top of the pier is equal to $3 \mathrm{~cm}$. The numerical analysis clearly shows that such partial configuration of the bay is stable, suggesting that, as an actual possibility, the bay might have been built without using auxiliary devices such as ties, as previously mentioned.

After the second construction phase, the maximum horizontal displacement at the pier decreases to $1.8 \mathrm{~cm}$ due to the application of the thrust of the central vault. As in the previous analysis step, the compressive damage does not affect any structural member in a significant way.

\subsection{Modelling of Long-term Deformation}

The analysis of the long-term deformation is carried out on the configuration and for the initial stress state resulting from the sequential analysis described in the previous section. No viscous deformation experienced in-between the construction phases has been considered.

As it can be inferred from Section 2.1, the evaluation of time-dependent deformation due to creep according to the adopted constitutive equation requires the definition of two parameters, i.e. the retardation time $\vartheta$ and the participation ratio $\xi$. A sensitivity analysis has been carried out in order to calibrate their values on the basis of the experimental data. As mentioned in Section 4.1, the rate of increase of the horizontal deformation of piers was measured as about 0.1 $\mathrm{mm} /$ year between 2003 and 2008. In the particular case of the $4^{\text {th }}$ bay, the monitoring activity was carried out between the years 543 and 548 after the completion of the structure (1460). The symmetric component of the pier horizontal displacement is $\delta_{s}=9.5 \mathrm{~cm}$ for the Section 4-5, as reported in Table 1. Making reference to this data, it has been possible to adjust the model parameters to the experimental behavior of the structure.

Fig. (6a) shows the time dependent increase of the horizontal displacement at the pier top for $\vartheta=34$ and $\xi$ equal to $0.875,0.925$ and 0.975 . It is worth noticing that the retardation time influences only the time scale of the analysis. Since the vertical loading is kept constant during the analysis, changing the value of $\vartheta$ would be equivalent to scale the curves of Fig. (6a) along the x-axis. On the other hand, the value of the participation ratio is more influential on the time dependent response. The calibration of this parameter shows the joint influence of long term deformation and geometric nonlinear effects on the stability of the structure. The assumed values are large enough to analyse the structure under adverse conditions, since they presume that a significant amount of stiffness is susceptible to creep. Each value of the participation ratio leads to different results. In case of $\xi=0.875$, the pier maximum horizontal time-dependent displacement reaches a stable value of $11 \mathrm{~cm}$ after 2,000 years. In case of $\xi=0.925$, the pier maximum horizontal time-dependent displacement reaches a value of $24 \mathrm{~cm}$ after 2,000 years. The assumption of $\xi=0.975$ in the frame of a nonlinear geometric analysis leads to the instability of the structure at 1,350 years.

The most representative displacement vs. time curve seems the one corresponding to $\xi=0.925$, as can be noticed in Fig. (6b) showing a zoom of the time dependent displacement curves on the neighborhood of the monitoring period. In this situation, the structure presents a horizontal displacement at the pier top of about $9.5 \mathrm{~cm}$ at around 543548 years, with a deformation rate of about $0.1 \mathrm{~mm} /$ year. Such values are comparable to those observed in Mallorca Cathedral, showing that the combination of long-term deformation and non-linear geometric effects may have played a significant role during the life of the structure.

It is possible to conclude that a failure condition in the long term can be represented only for a very high value of the participation ratio $(\xi=0.975)$, that is in disagreement with the experimental data derived from the monitoring activity. It must be noted, however, that this conclusion is based on some not fully verified hypothesis, and that changes on some of the values adopted (as for example, for the initial deformations) or the use of a different constitutive
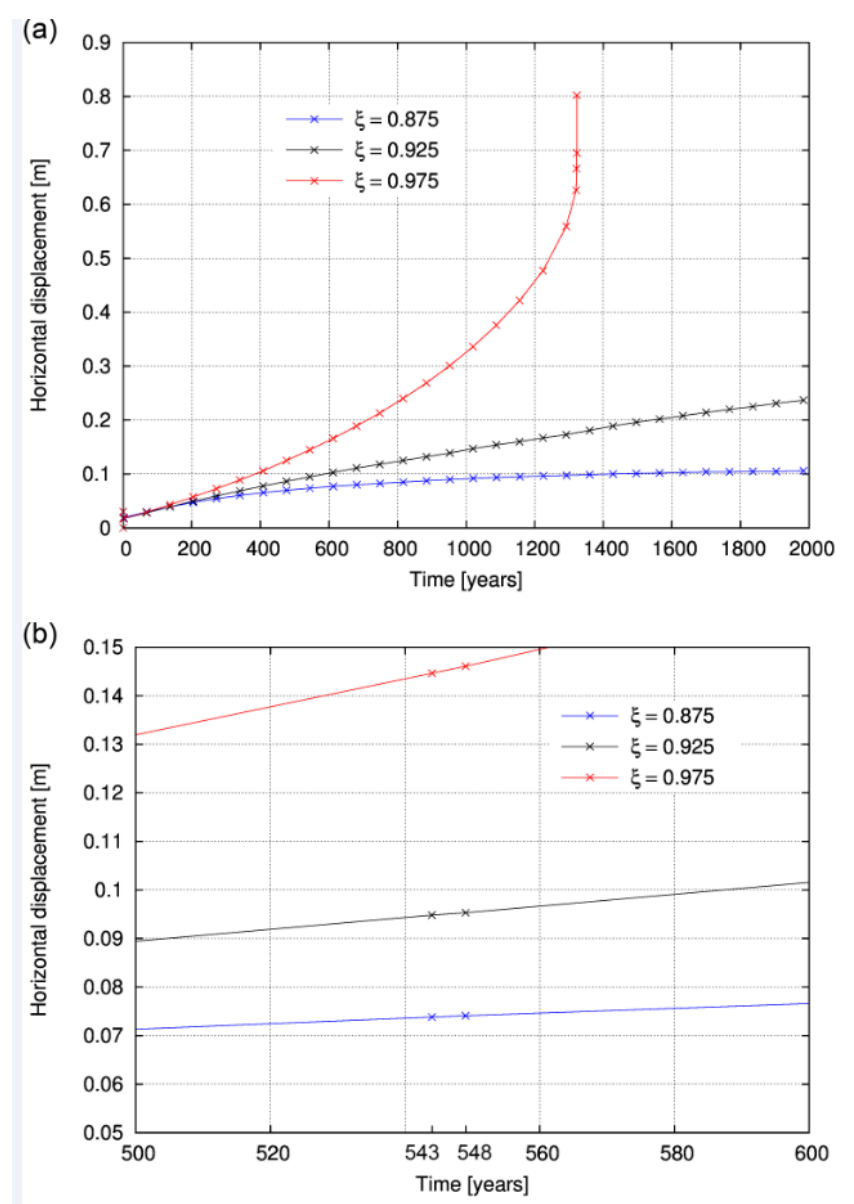

Fig. (6). FE simulation of long-term deformation: horizontal displacement increase at pier top due to creep (a), zoom of the curves on the neighborhood of the monitoring period (b). 
equation might lead to different results. In any case, the adopted numerical model seems to be effective in describing correctly the actual magnitude of deformations thanks to the sequential analysis simulating the building process and the description of the mechanical damage, viscous effects and geometric nonlinearity.

Fig. (7) shows the deformed shape and the tensile damage contour at the end of the analysis for $\xi=0.925$. Tensile damage occurs at the side towards the central nave, and also at the key of the aisle vault, at the transverse rib and at the bottom of the large window located in buttresses. The compressive damage does not affect any structural member in a significant way. Both displacements and tensile damage have increased more than at the end of the second construction stage, especially at the pier top and in the aisle vault, due to combined effect of long-term deformation and geometric non-linearity.

\section{CONCLUSIONS}

A viscoelasticity and damage model has been developed for the analysis of historical constructions. The specific format of the model leads to several advantages, especially in terms of simplicity and computational efficiency. The versatility of the theoretical framework ensures a suitable combination of the viscous effects with the mechanical damage in masonry material. The strain-driven format, the reduced number of internal variables and input parameters are remarkable features of the model.

The model has been implemented into a FE software and adopted for the study of a real large historical masonry structure. A tentative evaluation of the likelihood of a collapse due to geometrical instability in the long term has been carried out. The experimental data derived from a 5-year monitoring period have been considered to calibrate the parame-

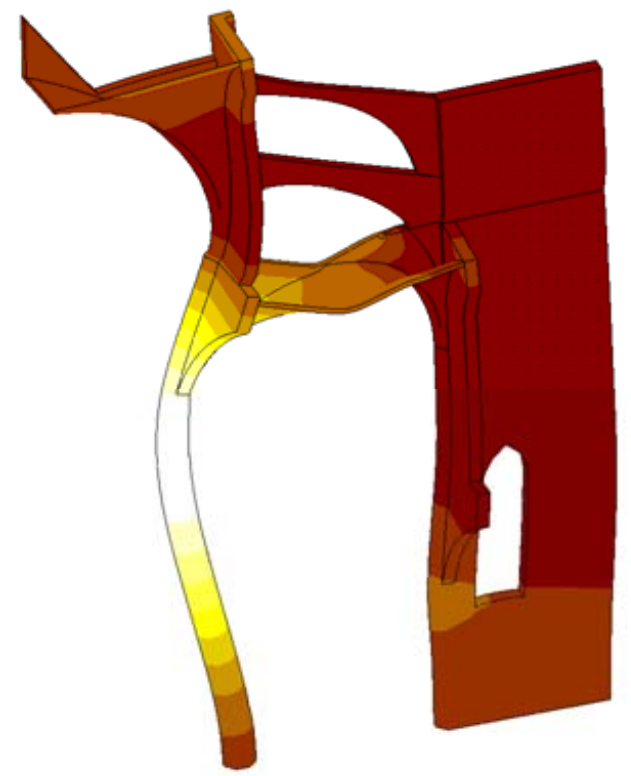

ters of the proposed model. A further monitoring period, now into consideration, would enable a more detailed estimation of the parameters involved. In particular, a more accurate estimation of current ratio of increasing irreversible deformation would permit an improved calibration of the parameters defining the viscous constitutive equation adopted to describe the deformation of the material.

\section{CONFLICT OF INTEREST}

The authors confirm that this article content has no conflicts of interest.

\section{ACKNOWLEDGEMENTS}

The studies presented here have been developed within the research project SEDUREC (CSD2006-00060), funded by DGE of the Spanish Ministry of Science and Technology, and project NIKER (contract agreement 244123) funded by the $7^{\text {th }}$ Frame Programme of the European Union, whose assistance is gratefully acknowledged.

\section{REFERENCES}

[1] L. Binda, A. Saisi, S. Messina and S. Tringali, "Mechanical damage due to long term behavior of multiple leaf pillars in Sicilian churches”, In $3^{\text {rd }}$ International Seminar on Historical Constructions, 2001, pp. 707-718.

[2] P. Roca, "Considerations on the significance of history for the structural analysis of ancient constructions”, In $4^{\text {th }}$ International Seminar on Structural Analysis of Historical Constructions, 2004, pp. 63-73.

[3] P. B. Lourenço and J. Pina-Henriques, "Collapse prediction and creep effects”, In Learning from Failure: Long Term Behavior of Heavy Masonry Structures, L. Binda, Ed. WIT Press: Southampton, 2008, pp. 57-80.

[4] A. Anzani, L. Binda and G. Mirabella Roberti, "Experimental researches into long-term behavior of historical masonry”, In Learning from Failure: Long Term Behavior of Heavy Masonry Structures, L. Binda, Ed. WIT Press: Southampton, 2008, pp. 29-56.

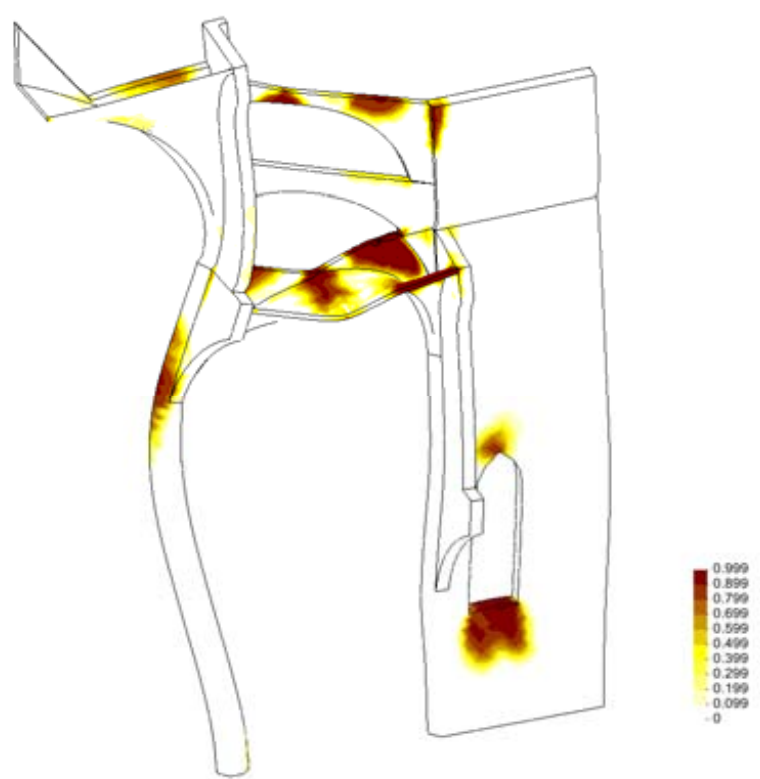

Fig. (7). FE simulation of long-term deformation: deformed shape (x10) with horizontal displacement contour (left) and tensile damage (right) for $\xi=0.925$. 
[5] L. Binda, G. Gatti, G. Mangano, C. Poggi and G. Sacchi Landriani, "The collapse of Civic tower of Pavia: a survey of materials and structure”, Masonry Int., vol. 6, pp. 633-642, 1992.

[6] L. Binda, A. Anzani and A. Saisi, "Failure due to long term behavior of heavy structures: the Pavia Civic Tower and the Noto Cathedral”, In $8^{\text {th }}$ International Conference on Structural Studies Repairs and Maintenance of Heritage Architecture, 2003, pp. 99-108.

[7] A. Anzani, L. Binda and G. Mirabella Roberti, "The effect of heavy persistent actions into the behavior of ancient masonry", Mater. Struct., vol. 33, pp. 251-261, 2000.

[8] C. Modena, M. R. Valluzzi, R. Tongini Folli and L. Binda, "Design choices and intervention techniques for repairing and strengthening of the Monza Cathedral bell-tower”, Constr Building Mater., vol. 16, pp. 385-395, 2002.

[9] E. Papa and A. Taliercio, "A visco-damage model for brittle materials under monotonic and sustained stresses”, Int. J. Numer. Anal. Methods. Geomech., vol. 29, pp. 287-310, 2005.

[10] E. Verstrynge, L. Schueremans, D. Van Germert and M. A. N. Hendriks, "Modelling and analysis of time-dependent behavior of historical masonry under high stress levels", Eng. Struct., vol. 33, pp. 210-217, 2010.

[11] A. Cecchi and A. Tralli, "A homogenized viscoelastic model for masonry structures”, Int. J. Solids Struct., vol. 49, pp. 1485-1496, 2012.

[12] R. Clemente, "Análisis estructural de edificios históricos mediante modelos localizados de fisuración” (in Spanish), Ph.D. Thesis, Technical University of Catalonia, Barcelona, Spain, 2006.

[13] M. Cervera, "Viscoelasticity and rate-dependent continuum damage models", Monography N No-79, CIMNE: Barcelona, 2003.

[14] M. Cervera, J. Oliver and R. Faria, "Seismic evaluation of concrete dams via continuum damage models", Earthquake Eng. Struct. Dyn., vol. 24, pp. 1225-245, 1995.

[15] R. Faria, J. Oliver and M. Cervera, “A strain-based plastic viscousdamage model for massive concrete structures", Int. J. Solids Struct., vol. 35, pp. 1533-1558, 1998.

[16] M. Cervera, L. Pelà, R. Clemente and P. Roca, "A crack-tracking technique for localized damage in quasi-brittle materials”, Eng. Fract. Mech., vol. 77, pp. 2431-2450, 2010.
[17] M. Cervera, E. Hinton and O. Hassan, "Nonlinear analysis of reinforced concrete plate and shell structures using 20-noded isoparametric brick elements", Comput. Struct., vol. 25, pp. 845869, 1987.

[18] L. Pelà, M. Cervera and P. Roca, "Continuum damage model for orthotropic materials: application to masonry”, Comput. Methods Appl. Mech. Eng., vol. 200, pp. 917-930, 2011.

[19] M. Cervera, J. Oliver and T. Prato, "Thermo-chemo-mechanical model for concrete. II: damage and creep”, J. Eng. Mech., vol. 125, pp. 1028-1039, 1998.

[20] J. Domenge, "L’obra de la Seu. El procés de construcció de la catedral de Mallorca en el trescents" (in Catalan), Palma de Mallorca, 1997.

[21] J. Domenge, “Análisis y estudio de los libros históricos de la Catedral. Documento $\mathrm{N}^{\circ}$ 3. Estudio, diagnóstico y peritación y en su caso planteamiento de actuaciones sobre el comportamiento constructivo-estructural de la catedral de Santa María, en la ciudad de Palma, isla de Mallorca (Baleares). Fase primera” (in Spanish), Barcelona: Technical University of Catalonia, 2003.

[22] P. Roca, "Description of Mallorca cathedral”, in Report of project Improving the Seismic Resistance of Cultural Heritage Buildings, EU-India Cross Cultural Programme, Barcelona: Technical University of Catalonia, 2004.

[23] L. Pelà, A. Aprile and A. Benedetti, "Seismic assessment of masonry arch bridges”, Eng. Struct., vol. 31, pp. 1777-1788, 2009.

[24] P. Roca, M. Cervera, G. Gariup and L. Pelà, "Structural analysis of masonry historical constructions. classical and advanced approaches”, Arch. Comput. Methods Eng., vol. 17, pp. 299-325, 2010.

[25] G. Martínez, "Vulnerabilidad sísmica para edificios históricos de obra de fábrica de mediana y gran luz" (in Spanish), Ph.D. Thesis, Technical University of Catalonia, Barcelona, Spain, 2007.

[26] M. Cervera, C. Agelet de Saracibar and M. Chiumenti, "COMET: Coupled mechanical and thermal analysis - data input manual version 5.0”, Technical report IT-308, CIMNE: Barcelona, 2002.

[27] "GiD: the personal pre and post-processor", CIMNE, Barcelona:2002. Available: http://gid.cimne.upc.es

Received: April 20, 2012

Revised: June 25, 2012

Accepted: June 28, 2012

(C) Roca et al.; Licensee Bentham Open.

This is an open access article licensed under the terms of the Creative Commons Attribution Non-Commercial License (http://creativecommons.org/licenses/ by-nc/3.0/) which permits unrestricted, non-commercial use, distribution and reproduction in any medium, provided the work is properly cited. 